\title{
Biochemical Markers for Differential Diagnosis of Stroke A Biochemical Markers Study of S100B Protein, Neuron Spesific Enolase (NSE), Myelin Basic Protein (MBP), and Heart-Type Fatty Acid Binding Protein (H-FABP)
}

\author{
Evy Liswati ${ }^{1}$, Andi Wijaya ${ }^{1.2}$, and Teguh A.S. Ranakusuma ${ }^{3}$
}

\section{B}

ACKGROUND: Differential diagnosis between hemorrhagic and ischemic stroke, which determine how to treat the patients, was performed by CT-Scan. CT-Scan is not always available in all Indonesian health care facility. Other alternative using biochemical markers needed to be studied.

METHODS: In total of 44 stroke patients consist of 25 ischemic and 19 hemorrhagic strokes according to CTScan, participated in this study. S100B Protein, NSE, MBP and H-FABP concentration in the blood of each stroke patient was determined.

RESULTS: Among the biochemical markers used, only MBP at cut off point $0,712 \mathrm{ng} / \mathrm{ml}$ could be used for diagnosing hemorrhagic from ischemic stroke for serum samples obtained until 72 hours after onset of the stroke. If samples could be obtained within 24 hours, S100B Protein and MBP could be used for diagnosing hemorrhagic from ischemic stroke. If both markers increased (S100B Protein $\geq 7,55 \mathrm{pg} / \mathrm{ml}$ and $\mathrm{MBP}>0,109 \mathrm{ng} / \mathrm{ml}$ ) sensitivity and specificity would be $77.8 \%$ and $84.6 \%$ respectively.

CONCLUSIONS:MBPandS100BProteinarepromising markers for differential diagnosis of hemorrhagic from ischemic stroke. Using serum samples obtained within 24 hours after onset and multiple markers (MBP and S100B Protein) will improved diagnostic performance of the test.

KEYWORDS: Stroke, S100B Protein, Neuron Specific Enolase, Myelin Basic Protein, and Heart-Type Fatty Acid Binding Protein
In Indonesia, stroke is the main cause of deaths in emergency room and major disability among middleage patients. The incidence rate of stroke is predicted higher in the future, along with increasing income and sedentary lifestyle.

Based on their pathology, stroke could be divided into hemorrhogic and ischemic stroke. Ischemic stroke need clot-dissolving agent, but the agent is a contraindication in hemorrhagic stroke $(1,2)$.

Routine differential diagnosis of hemorrhagic from ischemic stroke is performed by Computed Tomography (CT) Scan and Magnetic Resonance Imaging (MRI). Both instruments not always available in all Indonesian health care facility $(3,4)$.

Several neurospecific biomarkers for stroke have been studied. S100B Protein, NSE and MBP concentrations are elevated in the blood of stroke patients, and correlated significantly with National Institutes of Health Stroke Scale (NIHSS) (5). Heart-Type Fatty Acid Binding Protein (H-FABP) concentration is elevated in the blood of infarct and stroke patients (6).

\section{Patients and Methods}

\section{PATIENTS}

In total of 44 stroke adult patients consist of 25 ischemic and 19 hemorrhagic strokes according to CTScan participated in this study. Written consent from subjects or patient's family received before subjects were enrolled in this study. 


\section{ASSAYS OF BIOCHEMICAL MARKERS}

Serum S100B Protein, NSE and MBP concentrations were measured with Enzyme Linked Immuno Sorbent Assay kit from Syn X Pharma, Mississauga, CA. Serum H-FABP concentrations were measured with Enzyme Linked Immuno Sorbent Assay kit from Life Diagnostics, USA. Serum were separated from whole blood after centrifugation, and immediately kept at $-20^{\circ} \mathrm{C}$ until assays. All assays were performed according to manufacturers instruction.

For each run of serum S100B Protein, NSE and MBP, controls were included in the assays, and all results were within acceptable ranges. In our laboratory, the intraday imprecisions for all assays were lied between $4.2 \%-5.4 \%$.

\section{STATISTICAL ANALYSIS}

All statistical calculations were performed using SPSS ver 11.5, SPSS Inc. Chicago. Parametric or nonparametric calculations were chosen whichever appropriate based on the normality of the data. ChiSquare analysis was used to determine association significance of two nominal data. T-test or MannWhitney $U$ was used to compare means between two groups. ROC analysis was performed to determine cutoff point, and sensitivity and specificity at that point. Pearson or Spearman's Rho was used to determine correlation significance between two sets of data.

\section{Results}

All patients participated in this study are adults, men and women. There are not significant different of gender proportion ( $\mathrm{p}=0.901)$ and time to onset (0.232) between ischemic and hemorrhagic group.

Among four stroke biochemical markers: S100B Protein, NSE, MBP and H-FABP in which serum samples obtained up to 72 hours after onset, only MBP showed a significant different in concentration between ischemic and hemorrhagic group, $\mathrm{p}=0.000$.

The characteristics and serum biochemical marker concentrations of each group of all stroke patients are shown in table 1.

\section{Table 1. The characteristics and serum biochemical marker concentrations of each group of all stroke patients.}

\begin{tabular}{|l|c|c|c|}
\hline \multicolumn{1}{|c|}{ Variable } & Ischemic Group & Hemorrhagic Group & P-Value \\
\hline N & 25 & 19 & \\
Gender (\%Female) & 28.0 & 26.3 & 0.901 \\
Time to onset (mean \pm SD), hours & $16,5 \pm 13,6$ & $22,0 \pm 16,3$ & 0.232 \\
NSE (mean \pm SD), ng/ml & $7,31 \pm 9,45$ & $5,84 \pm 4,95$ & 0.991 \\
S100B Protein (mean \pm SD), pg/ml & $8,48 \pm 6,88$ & $17,78 \pm 30,68$ & 0.110 \\
MBP (mean \pm SD), ng/ml & $0,62 \pm 1,60$ & $3,10 \pm 4,08$ & $0.000^{* *}$ \\
H-FABP (mean \pm SD), ng/ml & $17,79 \pm 25,15$ & $18,27 \pm 15,21$ & 0.139 \\
\hline
\end{tabular}

** significance at $p<0.01$

If patients in which serum samples obtained after 24 hours are excluded, then S100B Protein and MBP showed a significant different in concentration between ischemic and hemorrhagic group, $p=0.030$ and 0.004 respectively.

Serum biochemical marker concentrations of each group of stroke patients which serum obtained within 24 hours after onset are shown in table 2. 
Table 2. Serum biochemical marker concentrations of each group of stroke patients
which serum obtained within 24 hours after onset

\begin{tabular}{|l|c|c|c|}
\hline \multicolumn{1}{|c|}{ Variable } & Ischemic Group & Hemorrhagic Group & P-Value \\
\hline N & 13 & 9 & \\
NSE (mean \pm SD), ng/ml & $5,21 \pm 4,49$ & $4,72 \pm 3,58$ & 0.845 \\
S100B Protein (mean \pm SD), pg/ml & $7,70 \pm 6,16$ & $26,1 \pm 43,3$ & $0.030^{*}$ \\
MBP (mean \pm SD), ng/ml & $0,25 \pm 0,38$ & $2,72 \pm 4,67$ & $0.004^{\star *}$ \\
H-FABP (mean \pm SD), ng/ml & $18,8 \pm 26,0$ & $17,7 \pm 13,7$ & 0.393 \\
\hline
\end{tabular}

* significance at $p<0.05$

** significance at $p<0.01$

Receiver Operating Characteristics (ROC) analysis showed that only area under curve of MBP $(\mathrm{p}=0.000)$ of up to 72 hours obtained samples significantly different from 0.5. But, if 24 hours samples obtained only, S100B Protein $(\mathrm{p}=0.030)$ and $\mathrm{MBP}(\mathrm{p}=0.006)$ showed area under curved significantly different from 0.5 .

Area under curve (AUC) of S100B Protein and MBP using serum samples obtained up to 72 hours and 24 hours are showed in Table 3.

\begin{tabular}{|l|c|c|c|c|}
\hline \multicolumn{1}{|c|}{ Biomarker } & \multirow{2}{*}{ AUC } & \multirow{2}{*}{ P Value= } & \multicolumn{2}{|c|}{$95 \% \mathrm{Cl}$} \\
\cline { 4 - 5 } & & & Lower & Upper \\
\hline $\begin{array}{l}\text { Up to 72 hours serum samples: } \\
\text { Protein S-100 }\end{array}$ & 0,642 & 0,110 & 0,477 & 0,808 \\
MBP & 0,822 & $0,000^{* *}$ & 0,699 & 0,945 \\
\hline Within 24 hours serum samples: & 0,778 & $0,030^{*}$ & 0,582 & 0,973 \\
Protein S-100 & 0,855 & $0,006^{* *}$ & 0,699 & 1,000 \\
MBP & & & & \\
\hline
\end{tabular}

* significance at $p<0.05$

** significance at $p<0.01$

Results showed that using serum samples obtained within 24 hours after onset, instead of up to 72 hours serum samples, improved performance of S100B Protein and MBP in differential diagnosis of hemorrhagic from ischemic stroke.

Further ROC analysis showed cutoff point, and sensitivity and specificity at the cutoff point. Table 4 showed cutoff point and its sensitivity and specificity for each marker in which the AUCs significantly differ from 0.5.

\begin{tabular}{|l|c|c|c|}
\hline \multicolumn{1}{|c|}{ Biomarker } & Cutoff & Sensitivity (\%) & Specificity (\%) \\
\hline Up to 72 hours serum samples: & & & \\
MBP & $0,712 \mathrm{ng} / \mathrm{ml}$ & 73,7 & 80,0 \\
\hline Within 24 hours serum samples: & & & \\
Protein S-100 & $7,55 \mathrm{pg} / \mathrm{ml}$ & 77,8 & 69,2 \\
MBP & $0,109 \mathrm{ng} / \mathrm{ml}$ & 88,9 & 69,2 \\
\hline
\end{tabular}

From Spearman's Rho correlation analysis, all s troke b iomarkers showed significant correlation each to another ( $r$ ranges from 0.35 to $0.70, p<0.05)$, except between NSE and MBP $(r=0.19, p=0.216)$. 


\section{Discussion}

The $\mathrm{m}$ ain purpose of $\mathrm{t}$ his research $\mathrm{i} \mathrm{s}$ limited to find $\mathrm{b}$ iomarkers which a re $\mathrm{c}$ apable to d ifferentiate hemorrhagic from ischemic s troke. I $n$ hemorrhagic stroke, patho-physiologically, there are more leucocytes especially Neutrofil and T-Cell infiltrate extravascular space of $\mathrm{t}$ he $\mathrm{b}$ rain $\mathrm{c}$ ompare $\mathrm{w}$ ith ischemic s troke. These inflammatory c ells a re $r$ esponsible $f$ or $t$ he damage of neurons and/or glial cells through radical oxygen s pecies. $\mathrm{M}$ arkers of neurons and/or g lial cells damage which leak i nto the circulation, c ould be detected in serum of the patients within hours after onset of the stroke. In the brain, glial cells are 50 times more prominent than neuron cells, so the rate limiting increase of biomarkers in the circulation is the number of leucocyte infiltrated. Markers of glial cells damage: S100B Protein and MBP would be higher in the circulation in hemorrhagic stroke compare $w$ ith ischemic stroke, because leucocytes infiltration in the hemorrhagic stroke a re higher than ischemic s troke. On the other hand, markers of neuron cells damage: NSE and H-FABP only slightly and not significantly increased i $\mathrm{n}$ hemorrhagic stroke $\mathrm{c}$ ompare $\mathrm{w}$ ith ischemic s troke, because the rate limiting increase of the biomarker in the serum is the number of the damage c ells theirsef. $S$ chematic explanation of the leak of stroke biomarkers into circulation after onset of the stroke is represented in figure 1 and 2.

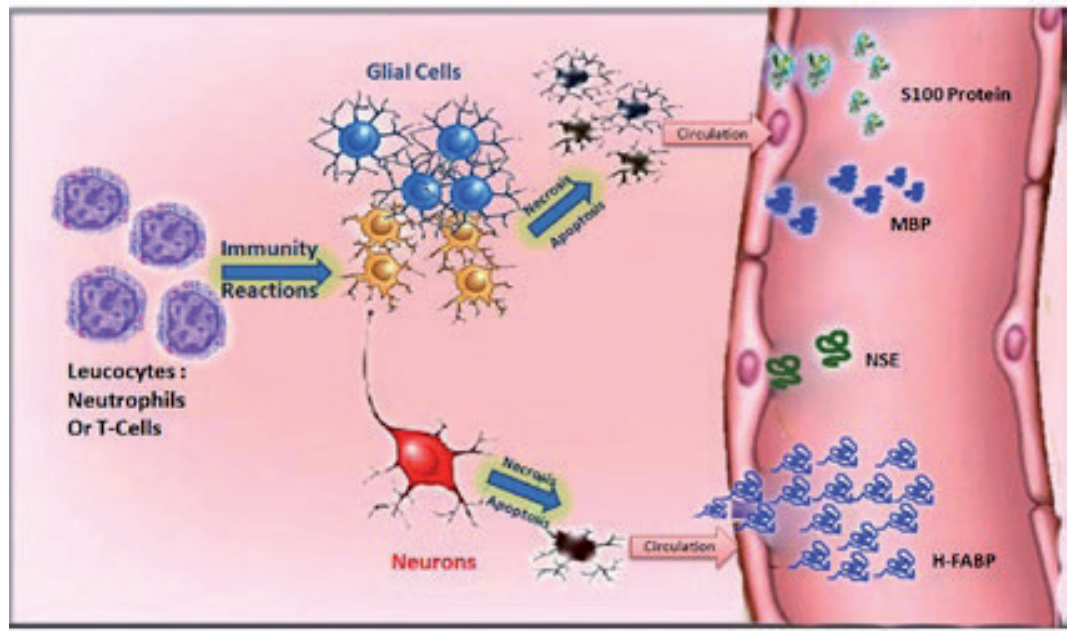

Figure 1. Schematic explanation of the leak of stroke biomarkers into circulation after onset of the ischemic stroke.

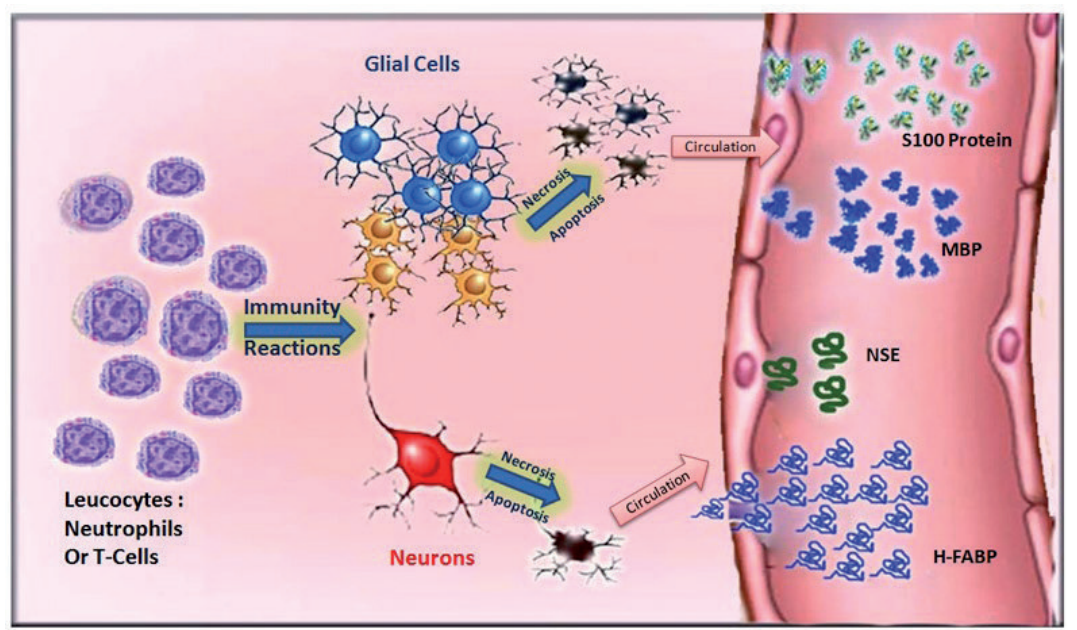

Figure 2. Schematic explanation of the leak of stroke biomarkers into circulation after onset of the hemorrhagic stroke. 
Only markers of glials cells damage in this study could be used for differential diagnosis of hemorrhagic stroke from ischemic stroke. Increased MBP concentration, from serum obtained within 24 hours after onset or up to 72 hours after onsert, is associated with hemorrhagic stroke. Increased S100B Protein concentration is associated with hemorrhagic stroke only if serum could be obtained within 24 hours after onset of the stroke. After 24 hours, a rapid increased of S100B Protein in serum also occured in ischemic stroke. Figure 3 below figure out the rapid increased of S100B Protein after Ischemic Stroke (7)

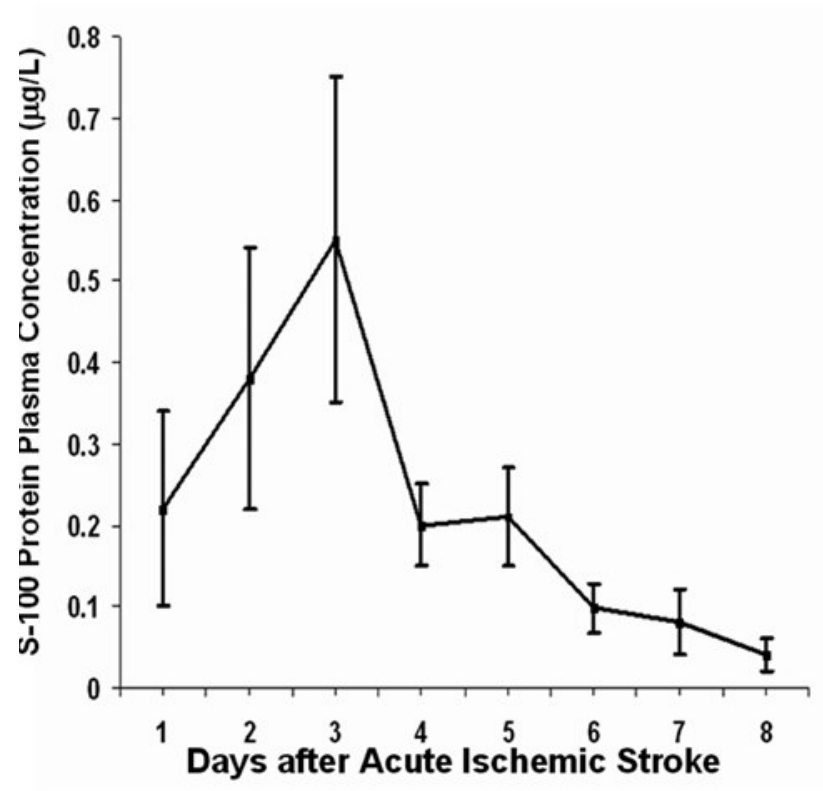

Figure 3. Plasma concentration of S100B Protein after Ischemic Stroke (Adapted from Missler, et al. 1997).
Further analysis indicated that using markers of glial cells damage: S100B Protein and MBP simultaneously could decreased missclasification from 5/22 (22.7\%) to $4 / 22(18.2 \%)$. Serum concentration of MBP equal or higher than $0,109 \mathrm{ng} / \mathrm{ml}$ and S100B Protein equal or higher than $7,55 \mathrm{pg} / \mathrm{ml}$, both using serum obtained within 24 hours after onset of the stroke, are associated with hemorrhagic stroke.

\section{Conclussion}

MBP and S100B Protein are promising markers for differential diagnosis of hemorrhagic from ischemic stroke. Using serum samples obtained within 24 hours after onset and multiple markers (MBP and S100B Protein) will improve diagnostic performance of the test.

\section{Acknowledgments:}

We thank The Prodia Foundation for Research and Training for their invaluable help in conducting the many procedures of this research.

\section{References}

1. Mc Phee et al., 2000. Stroke in Pathophysiology of Disease An Introduction to Clinical Medicine. New York : Mc Graw Hill, 3rd ed. 158-164.

2. Underwood, 2000, Cerebrovascular Disease in General and Systematic Pathology. Philadelphia : Churchill Livingstone. 3rd ed, 748-751.

3. Fassbender, K. Schmidt, R. Schreiner, H., et.al. 1997. Leakage of Brain-Originated Proteins in Peripheral Blood: Temporal Profile and Diagnostic Value in Early Ischemic Stroke. $J$ Neurol Sci. 148: 101-5.

4. Buttner, T. Weyers,S. Postert, T. Sprengelmeyer, R. Kuhn, W. 1997. S-100 Protein: Serum Marker of Focal Brain Damage After Ischemic Territorial MCA Infarction. Stroke. 28(10): 1961-5.

5. Hill, MD, Jackowski, G, Bayer, N, Lawrence, M, Jaeschke R, 2000. Biochemical Markers in Acute Ischemic Stroke. CMAJ. 162(8): 1139-40.

6. Zimmermann-Ivol, CG, Burkhard, PR, Floch-Rohr, JL, Allard, L, Hochstrasser, DF, Sanchez, JC. et al. 2004. Fatty Acid Binding Protein as a Serum Marker for the Early Diagnosis of Stroke. Molecular \& Cellular Proteomics. 3: 66-72.

7. Missler U. Wiesmann M. Friedrich C. Kaps M. 1997. S100 Protein and Neuron-Specific Enolase Concentrations in Blood as Indicators of Infarction Volume and Prognosis in Acute Ischemic Stroke. Stroke. 28:1956-1960. 